\title{
Effects of palladium on the optical and hydrogen sensing characteristics of Pd-doped ZnO nanoparticles
}

\author{
Anh-Thu Thi Do*, Hong Thai Giang, Thu Thi Do, Ngan Quang Pham \\ and Giang Truong Ho
}

\author{
Full Research Paper \\ Address: \\ Institute of Materials Science, Vietnam Academy of Science and \\ Technology, 18 Hoang Quoc Viet, Caugiay, Hanoi, Vietnam; Tel.: \\ +84-43-7569318; Fax: +84-43-8360705 \\ Email: \\ Anh-Thu Thi Do* - thudta@ims.vast.ac.vn; Thu Thi Do - \\ thudta@ims.vast.ac.vn \\ * Corresponding author \\ Keywords: \\ carrier dynamics; hydrogen sensing; Pd-doped $\mathrm{ZnO}$; \\ photoluminescence; sensor
}

Open Access

\author{
Beilstein J. Nanotechnol. 2014, 5, 1261-1267. \\ doi:10.3762/bjnano.5.140 \\ Received: 13 February 2014 \\ Accepted: 14 July 2014 \\ Published: 13 August 2014 \\ This article is part of the Thematic Series "Nanomanipulation and \\ environmental nanotechnology". \\ Guest Editor: E. Gnecco \\ (C) 2014 Do et al; licensee Beilstein-Institut. \\ License and terms: see end of document.
}

\begin{abstract}
The effect of palladium doping of zinc oxide nanoparticles on the photoluminescence (PL) properties and hydrogen sensing characteristics of gas sensors is investigated. The PL intensity shows that the carrier dynamics coincides with the buildup of the Pd-related green emission. The comparison between the deep level emission and the gas sensing response characteristics allows us to suggest that the dissociation of hydrogen takes place at $\mathrm{Pd}_{\mathrm{Zn}}$-vacancies $\left(\left[\mathrm{Pd}^{2+}\left(4 \mathrm{~d}^{9}\right)\right]\right)$. The design of this sensor allows for a continuous monitoring in the range of $0-100 \% \mathrm{LEL} \mathrm{H}_{2}$ concentration with high sensitivity and selectivity.
\end{abstract}

\section{Introduction}

Semiconductor zinc oxides $(\mathrm{ZnO})$ nanocrystals are not only interesting for fundamental physics, but they are also important for both optoelectronic and emerging electronic device applications, in particular for hydrogen sensing [1-6]. The key features and availability of $\mathrm{ZnO}$ nanocrystals in distributed discrete gas sensing devices crucially depend on the growth conditions. These conditions strongly influence their size, uniformity and defects. Optical properties and gas sensing characteristics in $\mathrm{ZnO}$ nanostructures are mainly expected to differ in terms of their quality from those in bulk materials. In $\mathrm{ZnO}$ bulk material, the sensitivity and selectivity are not sufficiently high. $\mathrm{ZnO}$ nanocrystals possess a large surface atom/bulk atom ratio [7], which corresponds to a higher sensitivity, thermal stability [8], compatibility with other nanodevices, and are potentially the best gas sensors. Oxides cannot easily distinguish between different types of gases, but the addition of certain noble metals as dopants can promote the gas-sensing performance [9-11]. Noble metal dopants in $\mathrm{ZnO}$ can modify the optical and electric properties of $\mathrm{ZnO}$, which influence the sensitive performance $[10,12]$. Palladium, a $4 \mathrm{~d}$ metal, is taken as an impurity in $\mathrm{ZnO}$. This is most likely caused by their special electronic configuration, i.e., $4 \mathrm{~d}$. Due to the sensitivity of the palladium ions with 
deep holes on singly ionized oxygen interstitials, $\mathrm{Zn}$ anti-site vacancies, and oxygen vacancies, it is of interest to find out whether Pd incorporated in $\mathrm{ZnO}$ significantly improves sensitivity and specificity for hydrogen $[13,14]$.

In this work, we have successfully synthesized Pd-doped $\mathrm{ZnO}$ nanoparticles for an application as gas sensors by a lowtemperature wet-chemical process. Photoluminescence (PL) measurements at room temperature are then carried out in order to determine the role of vacancies, trapping levels, and the transition shift of the PL emission maximum in these samples. In order to study and optimize the four main factors affecting the ability of hydrogen sensors, typical sensors based on $\mathrm{ZnO}$ nanoparticles have been designed. The hydrogen gas sensor based on $\mathrm{Pd}$-doped $\mathrm{ZnO}$ shows a relative fast response compared with the undoped sample. We also investigated the hydrogen sensing characteristics of these catalytic gas sensors in the measurement chamber containing hydrogen in air, with concentrations of $25-100 \%$ of the lower explosive limit (LEL), which is the minimum concentration of vapor or gas in air below which flame propagation does not occur on contact with a source of ignition [15]. The value of $25-100 \%$ LEL is equivalent to about 10,000-40,000 ppm. An existing correlation between the PL emissions and hydrogen sensing characteristics of these gas sensors will also be discussed.

\section{Results and Discussion}

$\mathrm{X}$-ray diffraction patterns of $\mathrm{ZnO}$ and $\mathrm{Pd} / \mathrm{ZnO}$ nanoparticles are presented in Figure 1. All the XRD peaks are indexed by a hexagonal wurtzite phase of ZnO (JCPDS card no. 36-1451). The results show that the Pd-doped $\mathrm{ZnO}$ sample has a better crystallinity, higher intensity and smaller peak width than those of the pure $\mathrm{ZnO}$ sample at $700{ }^{\circ} \mathrm{C}$ for 2 hours. For the $\mathrm{Pd} / \mathrm{ZnO}$ sample, crystalline phases of $\mathrm{ZnO}$ and $\mathrm{Pd}$ are found to be coexisting. This revealed that metallic Pd nanoparticles are dispersed in the $\mathrm{ZnO}$ matrix. The crystallite sizes estimated for the same samples from Scherrer's formula by using the full width at half maximum (FWHM) [16] from the XRD patterns is in the range of $12 \mathrm{~nm}$ to $20 \mathrm{~nm}$, giving average sizes of $\mathrm{ZnO}$ and $\mathrm{Pd} / \mathrm{ZnO}$ samples of 16.2 and $16.5 \mathrm{~nm}$ from all the peaks, respectively.

A more precise determination of the primary particle size is inevitably be accompanied by a significant error due to their aggregate nature and the formation of polycrystalline nanoparticles. Consequently, other methods were used to evaluate the particle size. This includes the Brunauer-Emmett-Teller (BET) surface area analysis and the Barrett-Joyner-Halenda (BJH) pore size and volume analysis. The obtained isotherms of the $\mathrm{ZnO}$ and $\mathrm{Pd} / \mathrm{ZnO}$ samples prepared in ethanol (Figure 2) correspond to a type III isotherm in the Brunauer classification $[17,18]$, which is characterized by the hysteresis loop, and it

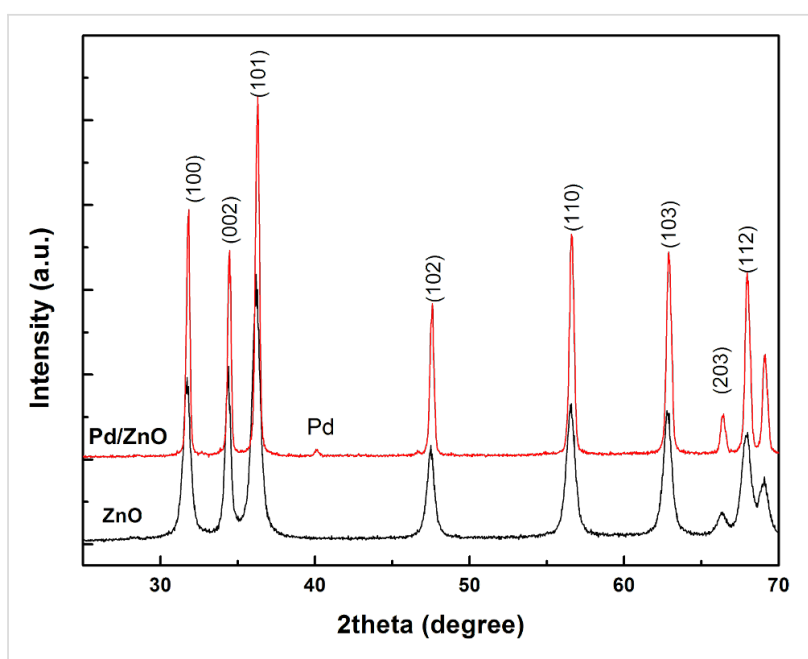

Figure 1: X-ray diffraction patterns of $\mathrm{ZnO}$ and $\mathrm{Pd} / \mathrm{ZnO}$ nanopowders.

does not exhibit any limiting adsorption at high relative pressures. The specific BET surface area of the $\mathrm{ZnO}$ and $\mathrm{Pd} / \mathrm{ZnO}$ samples were determined to be 37.5 and $34.32 \mathrm{~m}^{2} / \mathrm{g}$, respectively, the calculated BJH pore sizes were 8.7 and $10.6 \mathrm{~nm}$. Based on the measured BET surface area the size of the $\mathrm{ZnO}$ and $\mathrm{Pd} / \mathrm{ZnO}$ samples was estimated to be $28 \mathrm{~nm}$ and $31 \mathrm{~nm}$, respectively. Thus, BET data satisfactorily correlate with XRD results, and the discrepancy between BET and XRD data can be explained by the complicated geometry of the polycrystalline nanoparticles mentioned above.

To explore the effect of Pd on the optical properties of $\mathrm{ZnO}$ nanoparticles, photoluminescence (PL) spectra were measured. Figure 3 shows the PL spectra of $\mathrm{ZnO}$ and $\mathrm{Pd} / \mathrm{ZnO}$ samples with a $325 \mathrm{~nm}$ excitation at room temperature. For the $\mathrm{ZnO}$ sample a Gaussian fitting analysis shows that the broad emission band is a superimposition of three major peaks, one broad emission with a peak at around $408 \mathrm{~nm}$, a second emission band at $517 \mathrm{~nm}$, and a third emission band at around $570 \mathrm{~nm}$. The UV emission peak at about $408 \mathrm{~nm}(3.03 \mathrm{eV})$ corresponds to the near-band-edge emission of the $\mathrm{ZnO}$ crystal. The origins of this visible emission have been the subject of a long-standing controversy. It has been attributed to the transition between the electron near the conduction band and the deeply trapped hole, which is an oxygen/zinc vacancy containing no electrons $[19,20]$. It is also attributed to the transition between donor-acceptor pairs.

In the $\mathrm{Pd} / \mathrm{ZnO}$ sample, the excitonic band-edge emission completely vanished or was indistinct, while the structured green luminescence band and the transition shift of the emission maximum to higher energies was clearly visible. The second peak at $517 \mathrm{~nm}$ increased and the third peak at around $570 \mathrm{~nm}$ decreased. Interestingly, the obtained result is 


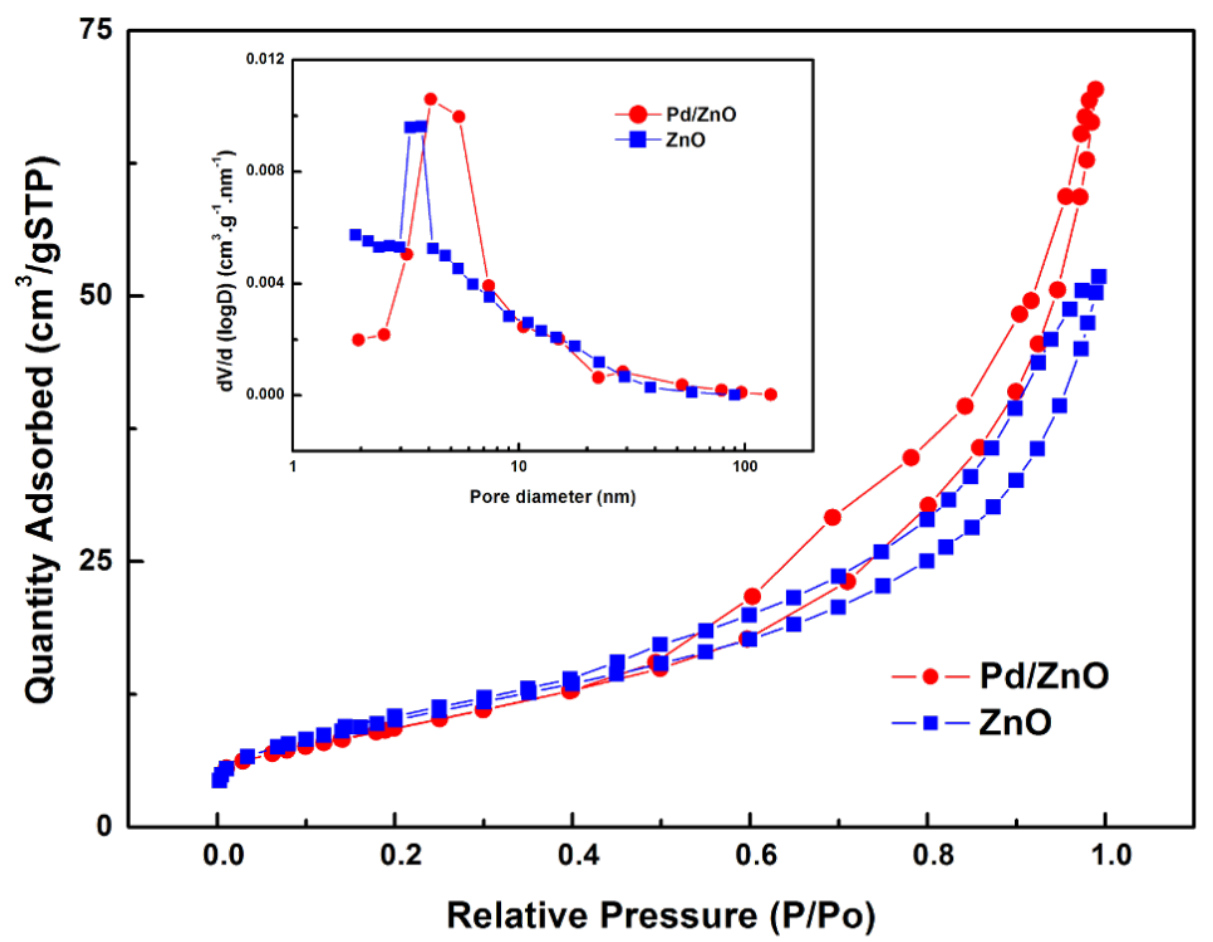

Figure 2: Typical nitrogen adsorption-desorption isotherm and BJH pore size distribution plots (inset) of $\mathrm{ZnO}$ and $\mathrm{Pd} / \mathrm{ZnO}$ nanoparticles.

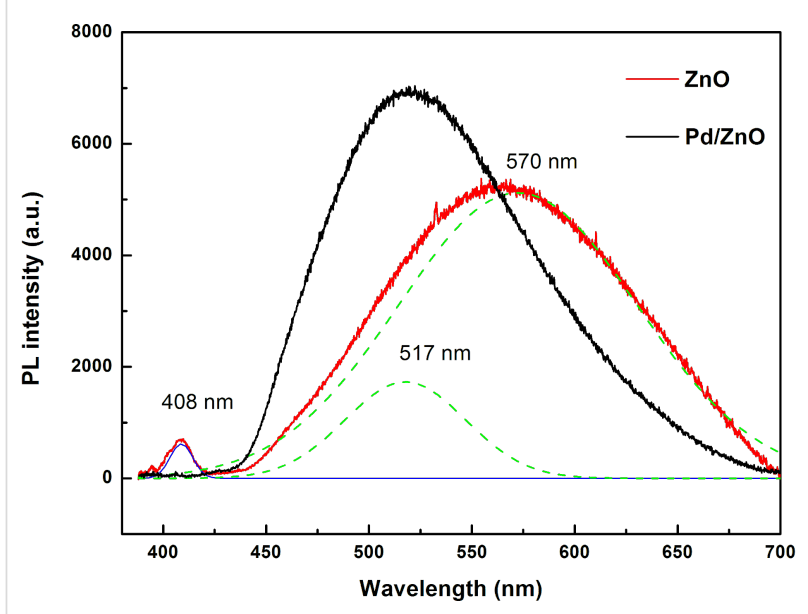

Figure 3: $\mathrm{PL}$ spectra of $\mathrm{ZnO}$ and $\mathrm{Pd} / \mathrm{ZnO}$ nanoparticles at room temperature.

confirmed by the similarity of the luminescence bands of $\mathrm{ZnO}$ and $\mathrm{ZnO}: \mathrm{Cu}$ [19-21]. The fine structure is assigned to the longitudinal optical phonon replica with an energy spacing of about $72 \mathrm{meV}$. This suggests that a green luminescence band originates from palladium ions, which replace zinc and always occur in $\mathrm{ZnO}$ in a small amount. The dominant peak at $517 \mathrm{~nm}$ corresponds to the exciton transition from the ground-state electronic subband to the ground-state of $\mathrm{Pd}$ in replacing $\mathrm{Zn}$ sites (i.e., $\mathrm{Pd}_{\mathrm{Zn}}$ vacancies). The excited state of $\mathrm{Pd}_{\mathrm{Zn}}$ originates from a hole bound to $4 \mathrm{~d}^{10}$ shells or an intermediately bound exciton to a neutral $d^{9}$ configuration due to the hybridization of the $\mathrm{Pd} 4 \mathrm{~d}$ states with the $\mathrm{Zn} 4 \mathrm{~s}$ states at the bottom of the conduction band. The electron capture takes place at the neutral $\mathrm{Pd}_{\mathrm{Zn}}$ center (i.e., $\left.\left[\operatorname{Pd}^{2+}\left(4 \mathrm{~d}^{9}\right)\right]\right)$, and the hole is captured by the potential created by the tenth electron to form the $\left[\mathrm{Pd}^{+}\left(4 \mathrm{~d}^{9}+e\right), h\right]$ state.

We now discuss the hydrogen sensing characteristics of catalytic gas sensors based on $\mathrm{ZnO}$ nanoparticles. For convenience, the fabricated sensors are denoted according to the used sensitive material. that is, sensor $1, \mathrm{ZnO}$ and sensor 2, $\mathrm{Pd} / \mathrm{ZnO}-0.5$ wt \% Pd. The characteristics of the sensor were examined in a measurement chamber containing hydrogen in the air at $25 \%$ of the lower explosive limit concentration (LEL) with a flow speed of $100 \mathrm{~mL} / \mathrm{min}$, at a temperature of $30{ }^{\circ} \mathrm{C}$, and a relative humidity of $65 \% \mathrm{RH}$. To keep the operating temperature of the sensor in the range of $200-300{ }^{\circ} \mathrm{C}$, an applied voltage $V_{\text {applied }}$ of $1.7 \mathrm{~V}$ and a current of about $120 \mathrm{~mA}$ are required. The obtained linear curve implied that it is possible to control the operating temperature by turning the applied voltage. To study the role of the Pd catalyst in the $\mathrm{ZnO}$ nanoparticles on the sensitivity of the sensor, the sensor output signal was measured as a function of the operating temperature of the sensor in $25 \%$ of the LEL concentration of hydrogen. The temperature of the microheater is tuned by changing the voltage

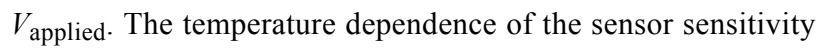
(through voltage $V_{\text {out }}$ ) is shown in Figure 4a. 

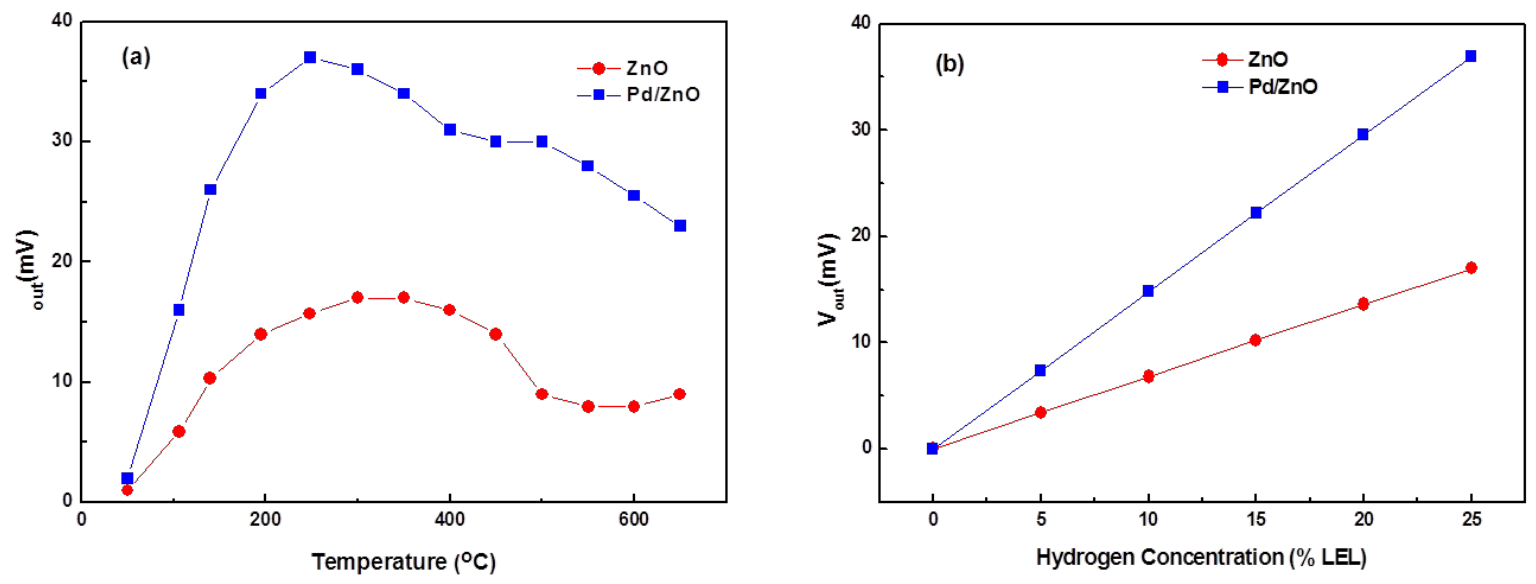

Figure 4: Dependence of (a) the operating temperature on the sensor sensitivity and (b) the hydrogen concentration on the sensor sensitivity (b).

These results indicate that the sensors have the greatest sensitivity within an operating temperature range of $200-300{ }^{\circ} \mathrm{C}$. Among the measured sensors, the highest sensitivity was found with the $\mathrm{Pd} / \mathrm{ZnO}$ sample. The values of the output voltage maximum, $V_{\text {out }}$, were 17 and $37 \mathrm{mV}$ for $\mathrm{ZnO}$ and $\mathrm{Pd} / \mathrm{ZnO}$ samples, respectively. An operating temperature of $250{ }^{\circ} \mathrm{C}$ was selected to investigate the gas-sensitive characteristics of the $\mathrm{Pd} / \mathrm{ZnO}$ sensor. With a flow speed of $100 \mathrm{~mL} / \mathrm{min}$ and a relative humidity of $65 \% \mathrm{RH}$, the linear dependence of the sensitivity of the $\mathrm{Pd} / \mathrm{ZnO}$-based sensor on hydrogen concentrations in the range of $0-25 \%$ LEL was observed as shown in Figure $4 b$.

The gas sensing mechanism usually accepted for semiconductor sensors explains the functionality due to reactions of hydrogen with the adsorbed oxygen species (i.e., $\mathrm{O}^{2-}$ or $\mathrm{O}^{-}$) on the surface of the oxide, which liberate free electrons and $\mathrm{H}_{2} \mathrm{O}$ thereby changing the conductivity of the material. The sensing mechanism for $\mathrm{H}_{2}$ at $250{ }^{\circ} \mathrm{C}$ can be explained by the Pd metal particles on the surface of $\mathrm{ZnO}$, which act as a catalyst. They dissociate hydrogen molecules into highly reactive atoms, which spread out on the surface of the semiconductor $\mathrm{ZnO}$ particles and reduce the potential barrier between the particles. In addition, the greater sensitivity to hydrogen can be explained because the oxidation of dissociated hydrogen is faster and more efficient than the decomposition and oxidation of hydrocarbons [22]. Moreover, as shown in Figure 3, the losing nearband-edge emission and transition shift of green luminescence band are due to $\mathrm{Pd}_{\mathrm{Zn}}$-vacancies. This allows us to note the correlation between the deep-level emission and the gas-sensing response characteristics of these samples. We suggest that the dissociation of hydrogen takes place at $\mathrm{Pd}_{\mathrm{Zn}}$-vacancies (i.e, $\left.\left[\operatorname{Pd}^{2+}\left(4 \mathrm{~d}^{9}\right)\right]\right)$ and may be expressed as,

$$
\mathrm{H}_{2}+\left[\mathrm{Pd}^{2+}\left(4 \mathrm{~d}^{9}\right)\right]+\mathrm{H}_{2} \rightarrow 4 \mathrm{H}\left[\mathrm{Pd}^{+}\left(4 \mathrm{~d}^{9}+\mathrm{e}\right)\right]
$$

Then, the oxidation of dissociated hydrogen happens according to the reaction,

$4 \mathrm{H}\left[\mathrm{Pd}^{+}\left(4 \mathrm{~d}^{9}+\mathrm{e}\right)\right]+\mathrm{O}_{2}^{-}{ }^{-}$(ads) $\rightarrow 2 \mathrm{H}_{2} \mathrm{O}+\left[\mathrm{Pd}^{2+}\left(4 \mathrm{~d}^{9}\right)\right]$

Similar results, viz. that the concentration of vacancies in turn controls the gas sensing characteristics, have been reported in $\mathrm{ZnO}$ films [23]. The sensitivity and selectivity characteristics of the gas sensor are associated with the deep hole-trap states and vacancies on the $\mathrm{ZnO}$ surface by the electron transfer mechanism [23,24]. The Pd metal nanoparticles modify the charge density on the $\mathrm{ZnO}$ surface, so that the incident electric field is changed [25], which not only affects the emission but also changes the oxygen adsorption and desorption of the gas sensors based on $\mathrm{Pd} / \mathrm{ZnO}$ nanocrystals.

For gas selectivity of the sensor based on $\mathrm{Pd} / \mathrm{ZnO}$ nanoparticles, the sensitivity of the $\mathrm{ZnO}-0.5 \mathrm{wt} \% \mathrm{Pd}$ sensor depends on the operating temperature. This is shown in Figure 5 for 1 vol $\%$ of hydrogen, $\mathrm{H}_{2}$, carbon monoxide, $\mathrm{CO}$, and for propane, $\mathrm{C}_{3} \mathrm{H}_{8}$. The comparison of the specificity of the sensor for the studied gases at $250{ }^{\circ} \mathrm{C}$ shows that the sensor is highly sensitive to $\mathrm{H}_{2}$ and less sensitive to $\mathrm{CO}$ and $\mathrm{C}_{3} \mathrm{H}_{8}$. Gas specificity of the sensor is evaluated in terms of the ratio of the sensitivity of the sensor for a particular gas and the sensitivity for other gases when compared under identical conditions ( $K_{\text {gas }} /$ different gas $)$. At $250{ }^{\circ} \mathrm{C}$, we found the ratios of $K_{\mathrm{H} 2 / \mathrm{CO}}=11.5$, and $K_{\mathrm{H} 2 / \mathrm{C} 3 \mathrm{H} 8}=5.1$. This confirms that the produced sensors display 

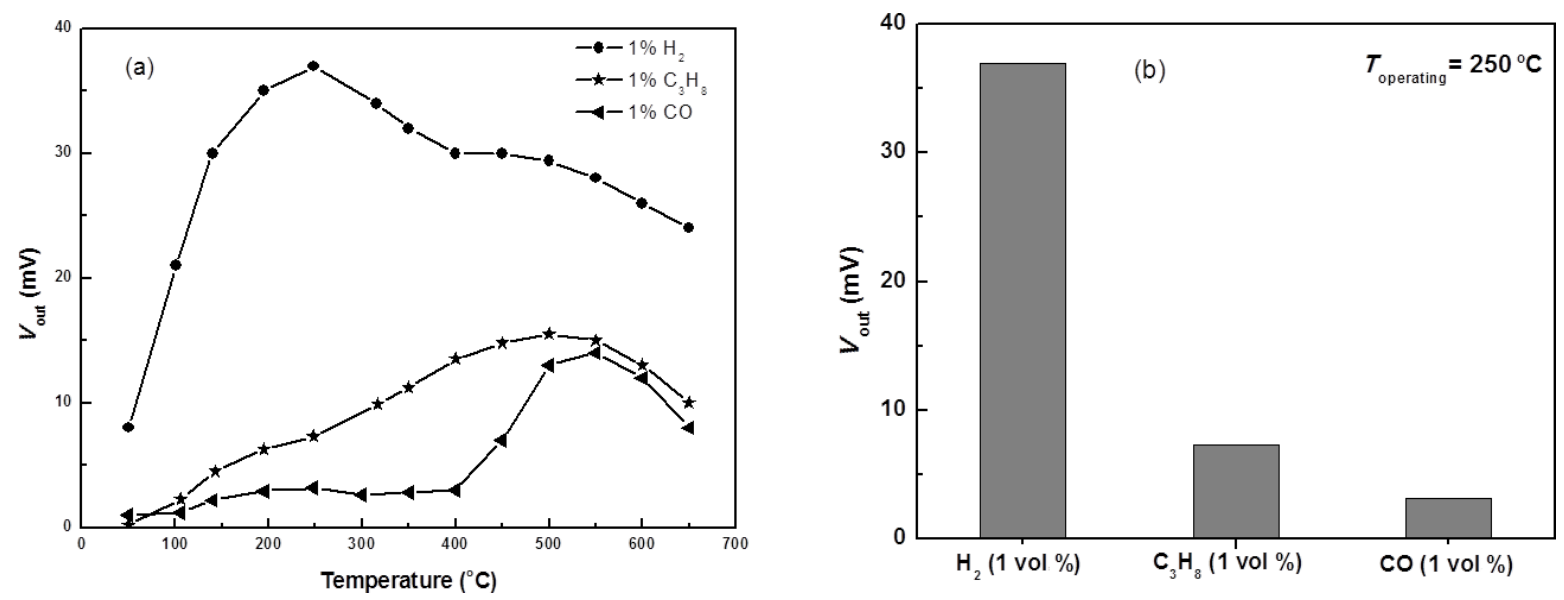

Figure 5: The operating temperature-dependence of (a) the sensitivity and (b) the specificity of the Pd/ZnO sample at 1 vol $\%$ of $\mathrm{H}_{2}, \mathrm{CO}$ and $\mathrm{C}_{3} \mathrm{H}_{8}$ with a humidity of $65 \% \mathrm{RH}$.

a good specificity for $\mathrm{H}_{2}$ compared to the cases of $\mathrm{CO}$ and $\mathrm{C}_{3} \mathrm{H}_{8}$. In fact, the effects of these gases on the hydrogen specificity of the sensor is insignificant because the concentration of $\mathrm{CO}$ in air is usually very low $(<100 \mathrm{ppm})$, much smaller than a concentration value of $1 \mathrm{vol} \%$ (ca. 10,000 ppm).

Figure 6 shows the characteristic of the sensor response to the $\mathrm{H}_{2}$ concentration of $25 \% \mathrm{LEL}$ at $250{ }^{\circ} \mathrm{C}$. The results show that the response time of the sensor is in the range of 10-20 s and the recovery time is around $10 \mathrm{~s}$. Thus, this sensor is quite suitable for designing portable equipment as well as online control equipment to measure $\mathrm{H}_{2}$ concentrations in the range of $0-100 \%$ LEL.

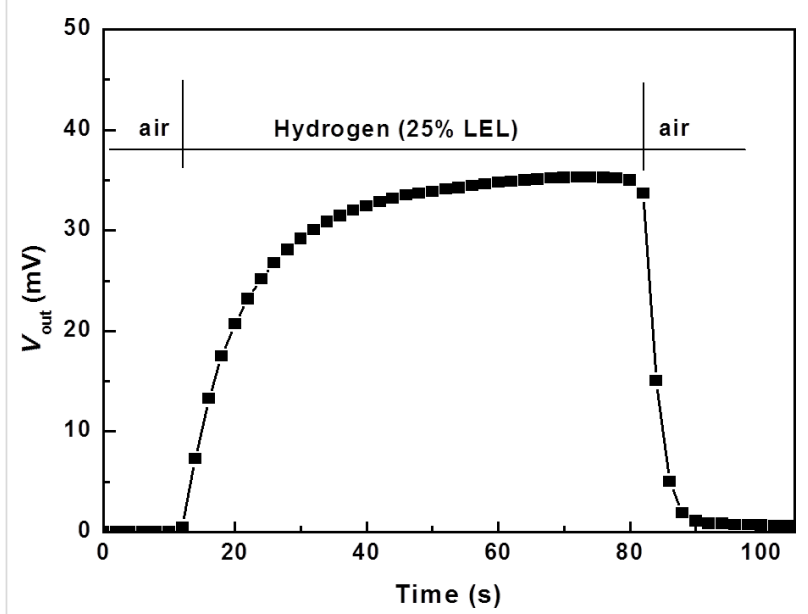

Figure 6: Response characteristics of the hydrogen sensor based on $\mathrm{Pd} / \mathrm{ZnO}$ nanoparticles.
Finally, to examine the stability of the sensor over time, the measured value of the sensor is recorded every day under two atmospheric conditions, namely, in air and in $\mathrm{H}_{2}$ concentrations of $25 \%$ LEL. The monitoring was carried out for 60 days, the results show that the sensor is rather stable with measured values fluctuated in the range of $\pm 3 \mathrm{mV}$ (Figure 7a). The stability of the sensor was also investigated by measuring a cycle at different concentrations of $\mathrm{H}_{2}$ (as shown in Figure $7 \mathrm{~b}$ ). For each concentration of $\mathrm{H}_{2}$, measurements were performed twice with an interval time of 20 minutes to minimize the effect of the previous measurements. The results show that the measured values are stable.

\section{Conclusion}

$\mathrm{ZnO}$ and $\mathrm{Pd} / \mathrm{ZnO}$ (with 0.5 wt \% $\mathrm{Pd}$ ) nanoparticles with a nanoscale particle size of 16.2 and $16.5 \mathrm{~nm}$ and with a large specific surface area of 37.5 and $34.32 \mathrm{~m}^{2} / \mathrm{g}$, respectively, were prepared by wet chemical methods for gas sensor fabrication. The PL spectra at room temperature show that the carrier dynamics coincides with the buildup of the Pd-related green emission. A novel gas sensor based on $0.5 \mathrm{wt} \% \mathrm{Pd}$ mixed with $\mathrm{ZnO}$ nanoparticles exhibited a high response to hydrogen at a relatively low temperature, from 200 to $300{ }^{\circ} \mathrm{C}$, and the best operating temperature of the sensor is at $250{ }^{\circ} \mathrm{C}$. We also showed that a qualitative correlation exists between the deep level emission and the gas sensing response characteristics of these samples. We suggest that the dissociation of hydrogen takes place at $\mathrm{Pd}_{\mathrm{Zn}}$-vacancies $\left(\left[\mathrm{Pd}^{2+}\left(4 \mathrm{~d}^{9}\right)\right]\right)$. The design of sensors as a catalytic membrane and Wheatstone bridge measurements allow for the continuous monitoring of the $\mathrm{H}_{2}$ concentration in the range of $0-100 \%$ LEL with high sensitivity and selectivity. 

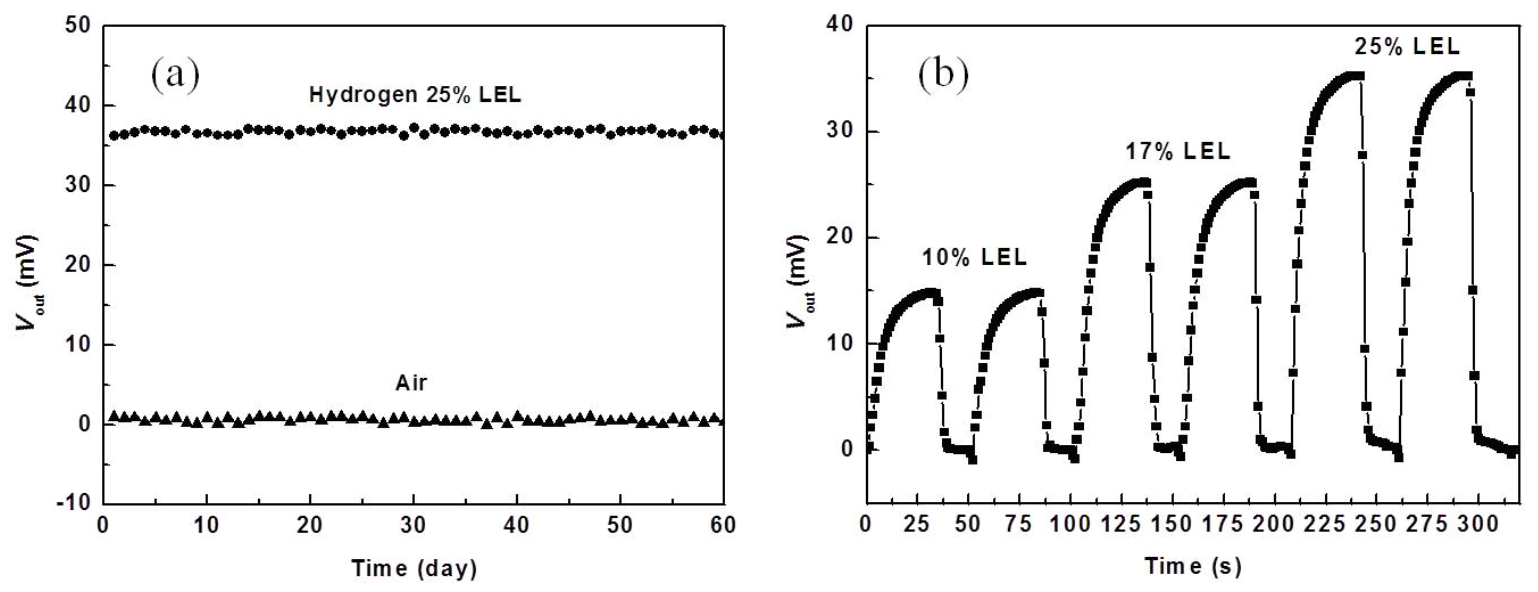

Figure 7: Stability over time of the investigated sensor as a function of (a) time and (b) in hydrogen atmosphere.

\section{Experimental}

$\mathrm{ZnO}$ nanopowders were synthesized by a wet chemical method with zinc acetate dihydrate, $\mathrm{Zn}\left(\mathrm{CH}_{3} \mathrm{COO}\right)_{2} \cdot 2 \mathrm{H}_{2} \mathrm{O}$, sodium hydroxide, $\mathrm{NaOH}$, and absolute ethanol (analytical reagents, Merck) as starting materials. In a typical procedure, $1.314 \mathrm{~g}$ of zinc acetate was dissolved in $300 \mathrm{~mL}$ solvent in a three-necked flask under stirring at $60{ }^{\circ} \mathrm{C} .0 .48 \mathrm{~g}$ of sodium hydroxide was added into this solution. After stirring for several minutes, a white precipitate appeared. The solution was stirred at $60{ }^{\circ} \mathrm{C}$ for 1 hour. After washing several times with distilled water and absolute ethanol, the particles were dried at $80{ }^{\circ} \mathrm{C}$ for $12 \mathrm{~h}$. $\mathrm{Pd}$-doping samples $(\mathrm{Pd} / \mathrm{ZnO})$ were obtained by mixing $\mathrm{ZnO}$ nanopowder with palladium chloride (Pd content in the sample is of $0.5 \mathrm{wt} \%$ ). All samples were calcined at $700^{\circ} \mathrm{C}$ for 2 hours to decompose the original chloride to obtain $\mathrm{Pd} / \mathrm{ZnO}$. The hydrogen sensors were improved on a pellistor gas sensor [26], which consisted of two resistors with $\mathrm{R}=500 \mathrm{Ohm}$, two platinum coils. Their thick membrane (about $10 \mu \mathrm{m}$ ) of $\mathrm{ZnO}$ pastes with/without $\mathrm{Pd}$ was coated onto one platinum coil (activated bead). $\mathrm{Al}_{2} \mathrm{O}_{3}$ paste was coated onto the last coil. The temperature of the beads is controlled by the operational electrical current passed through the platinum coils. At high temperatures the chemisorbed hydrogen molecules on the surface catalyst are oxidized with adsorbed oxygen to form water. The heat of combustion raises the temperature of the activated bead, which in turn changes the resistance of the activated coil. This creates an imbalance in the Wheatstone bridge circuit. In this case, the offset voltage is measured as the signal instead of resistance or conductivity values.

The temperature of the sensor was controlled by a UDP-1501 power supply (Unicorn, Korea) connected with a computer, and data were recorded automatically by using a Keithley model DMM-2700.
Crystalline phase analyses of synthesized samples were characterized by powder X-ray diffraction (XRD) with a Siemens D5000 diffractometer by using $\mathrm{CuK}_{\alpha}$ radiation. Morphologies of the samples were obtained by a Field Emission Scanning Electron Microscope (FE-SEM), Hitachi S-4800S. The specific surface areas of the prepared samples were determined by the BET (Brunauer-Emmett-Teller) method on a micromeritics system - AutoChem II 2920. The photoluminescence (PL) signals were dispersed by using an 1800 grating monochromator (Horiba iHR550) and then detected by means of a thermoelectrically cooled Si-CCD camera (Synapse).

\section{References}

1. Mitra, P.; Chatterjee, A. P.; Maiti, H. S. Mater. Lett. 1998, 35, 33-38. doi:10.1016/S0167-577X(97)00215-2

2. Chatterjee, P.; Mitra, P.; Mukhopadhyay, A. K. J. Mater. Sci. 1999, 34, 4225-4231. doi:10.1023/A:1004694501646

3. Wang, H. T.; Kang, B. S.; Ren, F.; Tien, L. C.; Sadik, P. W.; Norton, D. P.; Pearton, S. J.; Lin, L. Appl. Phys. Lett. 2005, 86, 243503. doi:10.1063/1.1949707

4. Tien, L. C.; Sadik, P. W.; Norton, D. P.; Voss, L. F.; Pearton, S. J.; Wang, H. T.; Kang, B. S.; Ren, F.; Jun, J.; Lin, J. Appl. Phys. Lett. 2005, 87, 222106. doi:10.1063/1.2136070

5. Verhelst, S.; Sierens, R. Int. J. Hydrogen Energy 2006, 26, 987-990. doi:10.1016/S0360-3199(01)00026-X

6. Bévenot, X.; Trouillet, A.; Veillas, C.; Gagnaire, H.; Clément, M. Sens. Actuators, B 2000, 67, 57-67. doi:10.1016/S0925-4005(00)00407-X

7. Wan, Q.; Li, Q. H.; Chen, Y. J.; Wang, T. H.; He, X. L.; Li, J. P.; Lin, C. L. Appl. Phys. Lett. 2004, 84, 3654-3656. doi:10.1063/1.1738932

8. Yonenaga, I. Phys. B (Amsterdam, Neth.) 2001, 308-310, 1150-1152. doi:10.1016/S0921-4526(01)00922-X

9. Liu, Z.; Li, J.; Ya, J.; Xin, Y.; Jin, Z. Mater. Lett. 2008, 62, 1190-1193. doi:10.1016/j.matlet.2007.08.010

10. Pawinrat, P.; Mekasuwandumrong, O.; Panpranot, J. Catal. Commun. 2009, 10, 1380-1385. doi:10.1016/j.catcom.2009.03.002 
11.Zeng, H.; Cai, W.; Liu, P.; Xu, X.; Zhou, H.; Klingshirn, C.; Kalt, H. ACS Nano 2008, 2, 1661-1670. doi:10.1021/nn800353q

12. Georgekutty, R.; Seer, M. K.; Pillai, S. C. J. Phys. Chem. C 2008, 112, 13563-13570. doi:10.1021/jp802729a

13. Hayakawa, I.; Iwamoto, Y.; Kikuta, K.; Hirano, S. Sens. Actuators, B 2000, 62, 55-60. doi:10.1016/S0925-4005(99)00303-2

14. Lupan, O.; Chai, G.; Chow, L. Microelectron. Eng. 2008, 85, 2220-2225. doi:10.1016/j.mee.2008.06.021

15. Reese, C. D.; Eidson, J. V. Handbook of OSHA Construction Safety and Health; Lewis Publishers: New York, NY, USA, 1999.

16. Yen, W. M.; Shionoya, S.; Yamamoto, H., Eds. Phosphor Handbook; CRC Press: Boca Raton, FL, USA, 1998.

17. Gregg, S. J.; Sing, K. S. W. Adsorption, Surface Area and Porosity, 2nd ed.; Academic Press: London, U.K., 1982.

18. Yu, J. C.; Xu, A.; Zhang, L.; Song, R.; Wu, L. J. Phys. Chem. B 2004, 108, 64-70. doi:10.1021/jp035340w

19. Garces, N. Y.; Wang, L.; Bai, L.; Giles, N. C.; Halliburton, L. E.; Cantwell, G. Appl. Phys. Lett. 2002, 81, 622-624. doi:10.1063/1.1494125

20. Schmidt-Mende, L.; MacManus-Driscoll, J. L. Mater. Today 2007, 10 , 40-48. doi:10.1016/S1369-7021(07)70078-0

21. Xing, G.; Xing, G.; Li, M.; Sie, E. J.; Wang, D.; Sulistio, A.; Ye, Q.-I.; Hon Alfred Huan, C.; Wu, T.; Sum, T. C. Appl. Phys. Lett. 2011, 98 , 102105. doi:10.1063/1.3558912

22. Heiland, G.; Kohl, D. Physical and Chemical Aspects of Oxidic Semiconductor Gas Sensors. In Chemical Sensor Technology; Seiyama, T., Ed.; Kodansha: Tokyo, Japan, 1988; Vol. 1, pp 15-38. doi:10.1016/B978-0-444-98901-7.50007-5

23. Pati, S.; Majumder, S. B.; Banerji, P. J. Alloys Compd. 2012, 541, 376-379. doi:10.1016/j.jallcom.2012.07.014

24. Alenezi, M. R.; Henley, S. J.; Emerson, N. G.; Silva, S. R. P. Nanoscale 2014, 6, 235-247. doi:10.1039/c3nr04519f

25. Zhang, D.; Wang, P.; Murakami, R.-i.; Song, X. Appl. Phys. Lett. 2010, 96, 233114. doi:10.1063/1.3442916

26. Hübert, T.; Boon-Brett, L.; Black, G.; Banach, U. Sens. Actuators, B 2011, 157, 329-352. doi:10.1016/j.snb.2011.04.070

\section{License and Terms}

This is an Open Access article under the terms of the Creative Commons Attribution License (http://creativecommons.org/licenses/by/2.0), which permits unrestricted use, distribution, and reproduction in any medium, provided the original work is properly cited.

The license is subject to the Beilstein Journal of Nanotechnology terms and conditions: (http://www.beilstein-journals.org/bjnano)

The definitive version of this article is the electronic one which can be found at: doi:10.3762/bjnano.5.140 